Revista lus et Praxis, Año 23, № 1, 2017, pp. 273 - 304

ISSN 0717 - 2877

Universidad de Talca - Facultad de Ciencias Jurídicas y Sociales

La inexistencia en el proceso civil: un análisis crítico

Felipe Gorigoitía Abbott

Trabajo recibido el 14 de noviembre de 2015 y aprobado el 25 de abril de 2016

\title{
La inexistencia en el proceso civil: un análisis crítico*
}

NULLITY IN THE CIVIL PROCESS: A CRITICAL ANALYSIS

Felipe Gorigoitía Авbott ${ }^{* *}$

\section{RESUMEN}

El presente artículo pretende hacer un estudio crítico de la inexistencia como categoría relevante dentro de la ineficacia de los actos procesales. Para esto analiza lo que la doctrina ha dicho tradicionalmente sobre ella, sus características y dificultades y la propone como una cuestión que debe ser tratada desde la perspectiva de la nulidad procesal. Termina postulando vías de mejoramiento de la nulidad, en particular, una vez concluido el juicio como alternativa a la inexistencia.

\section{ABSTRACT}

This article intends to make a critical study of the nullity as a relevant category within the invalidity of procedural acts. For this, it analyzes what the doctrine has traditionally said about it, its characteristics and difficulties and proposes it as an issue that must be treated from the perspective of procedural nullity. It finishes suggesting ways to improve nullity, particularly after the conclusion of the trial as an alternative to nullity.

$$
\begin{gathered}
\text { PALABRAS CLAVE } \\
\text { Inexistencia, Nulidad procesal, Cosa juzgada. } \\
\text { KeYwORDS } \\
\text { Nullity, Procedural nullity, Claim preclusion. }
\end{gathered}
$$

\section{Introducción}

La doctrina procesal civil chilena en general ha admitido a la inexistencia como una categoría relevante al momento de describir el sistema de ineficacias de nuestro proceso civil. Ya en 1928, Urrutia sostenía que se trata de una materia "de un interés práctico y teórico que no se puede desconocer"1. En

\footnotetext{
* El presente artículo es parte del Proyecto Fondecyt Iniciación № 11140786, denominado "La inexistencia en el contexto de la nulidad procesal", del cual el autor es investigador responsable. Agradezco los valiosos aportes de Hiam Ayllach Díaz, profesora de Derecho Procesal de la Universidad de Viña del Mar, y Paulina Fredes Cruz, estudiante de Derecho de la Universidad de Valparaíso, en la elaboración de este artículo.

** Felipe Gorigoitía Abbott, Doctor en Derecho, Profesor Adjunto de Derecho Procesal, Escuela de Derecho, Universidad de Valparaíso, Chile, correo electrónico: felipe.gorigoitia@uv.cl.

1 URRUTIA (1928), p. 71. La inspiración chiovendana de la frase es evidente, poco antes Chiovenda había dicho que "Si esta diferenciación es discutible en la esfera del derecho sustancial, resulta, en cambio, necesaria, teórica y prácticamente, en el proceso". CHIOvenDA (1925), p. 104.
} 
línea con la doctrina procesal extranjera más clásica ${ }^{2}$, tradicionalmente, entre nuestros autores se ha reconocido a la categoría ${ }^{3}$. En los últimos años, aunque con muy distinta extensión, Carrasco ${ }^{4}$ y Bocksang ${ }^{5}$ han planteado también la conveniencia de su reconocimiento.

La jurisprudencia ha aceptado la inexistencia, aunque de forma excepcional. El caso paradigmático sobre el tema es la sentencia de 24 de mayo de 2000 de la Corte de Apelaciones de Santiago en la causa caratulada "Novoa Chevesich con Servicio de Impuestos Internos" (rol No 2540-1999) ${ }^{6}$. Luego de ejecutoriada la sentencia, y con ocasión de la apelación de un incidente de nulidad promovido por la demandada basado en la disolución de la sociedad demandante, la Corte para declarar la nulidad de todo lo obrado en el juicio, postula "Que son requisitos para que un juicio tenga existencia jurídica, la existencia de un juez que ejerza jurisdicción, la de las partes, y la de un conflicto o litigio; a ello cabe agregar que haya existido un emplazamiento válido. La falta de concurrencia de alguno de ellos acarrea necesariamente la inexistencia del juicio" ${ }^{\prime 7}$.

La aceptación de la categoría ha tenido su expresión más significativa con ocasión del Proyecto de Código Procesal Civil (PCPC) ${ }^{8}$, que en su artículo 116 establece: "Inexistencia. La constatación de la inexistencia de los actos verificados, como ocurre con los practicados por o ante un órgano que no ejerza jurisdicción, se verificará, en cualquier tiempo, y sin más condiciones que la de citar previamente a los interesados. Excepcionalmente, en caso de falta de notificación de la demanda al demandado, dicha declaración deberá solicitarse dentro de los diez días siguientes desde que aparezca o se acredite que tuvo conocimiento personal del juicio".

Lo expuesto invita a un análisis de esta categoría, a fin de determinar sus alcances y las dificultades que puede suponer su aceptación. Para esto se

\footnotetext{
2 Alsina (1958), p. 100; Couture (2010), p. 340; Serra (1969), p. 460.

3 Tavolari (2000), p. 248; Colombo (1997), p. 423; Loyola (2001), p. 30; Salas (2000), p. 75; Otero (2009), p. 42; Pozo (1991), p. 63.

${ }^{4}$ Carrasco (2012).

5 BOCKSANG (2013).

${ }^{6}$ Sobre él, Romero (2001), pp. 781 y ss.

7 La inexistencia no aparecía ni en el Anteproyecto de Código ni en el Proyecto del año 2009 (boletín № 6.567-07). Sí había una referencia muy breve a la necesidad de regular el Informe del Foro para la Reforma Procesal Civil. En el diagnóstico de la situación actual de la regulación de la nulidad procesal sostiene que: "El CPC regula solamente la nulidad como causal de ineficacia de las actuaciones procesales, omitiendo la referencia a la inexistencia, la inoponibilidad y la preclusión. Ello no ha resultado hasta la fecha un inconveniente para la aplicación de dichas causales de ineficacia".
}

${ }^{8}$ Boletín No 8197-07. 
estudiará, primero, lo que ha dicho la doctrina acerca de la inexistencia y su tratamiento procesal. Posteriormente, su relación con la nulidad y los casos en que ella puede resultar relevante, para concluir con una propuesta acerca del mejoramiento de las vías existentes como una alternativa a la regulación de la inexistencia que propone el PCPC.

\section{2. ¿Cuándo se está frente a una inexistencia?}

\subsection{La inexistencia como falta de un requisito esencial}

La caracterización de la inexistencia en la doctrina tradicional es relativamente uniforme. Se suelen citar las palabras de Couture para graficar el tema, quien sostiene que "el concepto de inexistencia se utiliza, pues, para denotar algo que carece de aquellos elementos que son de la esencia y de la vida misma del acto; un quid incapaz de todo efecto" ${ }^{\prime \prime}$. En términos similares, Serra dice que son inexistentes aquellos actos "en que faltan los presupuestos esenciales para el nacimiento del acto procesal"10. En la doctrina nacional, Tavolari afirma que "el elemento diferenciador de un acto inexistente es la ausencia en aquel, de elementos constitutivos esenciales"11. Salas, por su parte, los caracteriza como aquellos "que carecen de las condiciones indispensables para ser concebidos"12.

Como se puede apreciar, para la caracterización del acto inexistente se emplea una concepción estructural de los actos jurídicos tomada del derecho privado, en la que se distinguen requisitos esenciales de aquellos de validez ${ }^{13}$. En esta perspectiva, determinar qué es un requisito esencial es, como advertía Chiovenda a principios del siglo pasado, "un campo de infinitas cuestiones"14.

Conscientes de esta dificultad, Carrasco y Bocksang, en los más recientes intentos por reivindicar la inexistencia, se desprenden de la noción de requisitos esenciales, para postular su aplicación desde otras perspectivas.

${ }^{9}$ Couture (2010), p. 349.

10 SerRa (1969), p. 460.

11 TaVolari (2000), p. 248.

12 Salas (2000), p. 75.

13 Una crítica a ellos se puede ver en Lourido (2003), pp. 19 y ss.; también en CarRASCO (2012), pp. 54 y ss.

${ }^{14}$ Chiovenda (1949), p. 150. Esta crítica está hecha a la luz del artículo 56 del Codice de procedura civile de 1865 que incluía este criterio como determinante de la nulidad y que sería reemplazado en el Codice de 1942. A pesar de esta advertencia, algunos autores reivindican la metafísica búsqueda de la esencia. MORón dice que la búsqueda "ha de realizarse con la indagación y examen de su definición, para luego ver si esa esencia concurre o no en el acto cuestionado, es el único criterio de validez científica para tratar el problema sustantivo de la inexistencia procesal". 
Carrasco, junto con constatar que desde la perspectiva orgánica del acto procesal la inexistencia no logra diferenciarse de la nulidad ${ }^{15}$, postula que ella debe reservarse para aquellos casos excepcionales en los que el acto no logra apariencia de juridicidad ${ }^{16}$. Agrega que "en la hipótesis contraria, esto es, si un determinado acto procesal reviste una apariencia de juridicidad, no puede sostenerse que es un acto inexistente y que ningún efecto produce, sino que por el contrario, el acto genera efectos los que podrán ser suprimidos en el evento que se origine un perjuicio trascendente a alguna de las partes, pero no a través de la inexistencia, sino que de la nulidad procesal"17. Para ejemplificar, emplea el caso de una notificación defectuosamente realizada, atribuyéndole la calidad de inexistente jurídicamente a aquella que no es realizada por un ministro de fe (por carecer de apariencia de juridicidad) de aquella realizada por un ministro de fe, pero en un domicilio incorrecto ${ }^{18}$.

La tesis de Bocksang descarta cualquier criterio general de identificación de esta figura. Insta, en vez de ello, a una aplicación tópica de la inexistencia, en la que al legislador, a lo más, le cabría la posibilidad de establecer algunos casos en los que ella se puede verificar, pero sin limitarla a defectos determinados, por cuanto "al pretender cercenarla de plano de un régimen jurídico, o limitarla a ciertos casos taxativamente establecidos, ella tiende a filtrarse y ser aplicada praeter o incluso contra legem ${ }^{\prime 19}$. A continuación, identifica un conjunto de situaciones en las que podría verificarse ésta, relativas a la investidura regular de los jueces, la competencia, asuntos de forma y asuntos de fondo ${ }^{20}$.

\section{2. ¿Tiene sentido regular lo inexistente?}

Sería un absurdo abordar jurídicamente aquello que no existe o que no es. Lo propiamente inexistente no tiene relevancia jurídica. Hablar de una sentencia o de un juicio inexistente en donde no se ha realizado actuación alguna, más allá de ser una constatación, no tiene mayor importancia, pues no hay tras de ello ninguna situación susceptible o digna de ser regulada. Como explica Guarinoni "caracterizar a algún hecho empírico como 'no existente' significa

15 Carrasco (2012), p. 255.

${ }^{16}$ Carrasco (2012), p. 252.

17 Carrasco (2012), p. 252.

${ }^{18}$ En la doctrina civil, una postura con la misma inspiración ha sido defendida por BARAONA (2011), pp. 36 y ss.

19 BoCKSANG (2013), p. 598.

${ }^{20}$ BOCKSANG (2013), pp. 599-601. 
que no tiene ninguna propiedad, salvo la de no existir" ${ }^{21}$. Es a lo que Carrasco llama inexistencia ontológica ${ }^{22}$.

Tras la contradicción terminológica que supone clasificar de inexistente un acto, se esconde el verdadero campo de actuación de esta figura, que es el de aquellos actos que, si bien existen, no reúnen las características para ser reputados como lo que, por una u otra vía, se pretende que sean ${ }^{23}$. En palabras de Carnelutti, "el significado de inexistencia se modifica, en el sentido de expresar en realidad no el no acto, sino el grado inferior o, mejor dicho, ínfimo del acto ineficaz" 24 .

Sin embargo, la categoría sigue sin ser relevante en casos de actos que no tienen ninguna cercanía con aquello que se toma como referencia para predicar su inexistencia. Santamaría da un ejemplo particularmente gráfico: "Así, si dos personas no llegan a un acuerdo sobre la compra de una cosa, no es incorrecto, lingüísticamente hablando, decir que se trata de una compra inexistente; pero al tratarse de un concepto negativo, con igual corrección formal se podría decir que un testamento, una norma jurídica o-ad absurdum- una discusión callejera son efectivamente, contratos de compraventa inexistentes, puesto que ningún contrato ha sido realizado" 25 .

Llegados a este punto, la postura tradicional parece decantarse por requerir que los actos respecto de los que se pueda declarar la inexistencia tengan alguna pretensión de validez, debido a la semejanza o proximidad con aquel que se emplea como referencia ${ }^{26}$. Así se ve en los ejemplos clásicos que se dan respecto del tema, como la sentencia sin firma ${ }^{27}$ o el juez que carece de jurisdicción ${ }^{28}$.

En resumen, el acto respecto del que se va a predicar la inexistencia no sólo debe existir sino, además, tener cierta pretensión de validez. Está lejos, como se ve, de ser nada. ¿Cómo se diferencia, entonces, de la nulidad? Consciente de esta dificultad es que Carrasco propone, como ya se explicaba, que el acto deba carecer de apariencia de juridicidad ${ }^{29}$. Algo parecido postula Palacio al decir

21 GuarinONi (2002), p. 21.

22 Carrasco (2012), p. 252.

${ }^{23}$ Guarinoni (2002), p. 21.

${ }^{24}$ Carnelutti (1944), p. 559.

25 Santamaría (1972), p. 204.

26 SANTAMARía (1972), p. 204.

27 SALAS (2000), p. 76.

28 Otero (2009), p. 45; Colombo (1997), p. 428.

${ }^{29}$ Carrasco (2012), p. 252. 
que el acto inexistente produce "una repulsa ideológica que lo priva de vigencia y lo descalifica como acto jurídico existente" ${ }^{\prime \prime 30}$. Si se asume que se requiere al mismo tiempo tanto pretensión de validez como ausencia de apariencia, en la práctica se transforma en una cuestión por poco irrelevante.

Aunque a veces sin explicitarlo ${ }^{31}$ de los catálogos que se entregan de lo que serían actos inexistentes, se puede apreciar que la distinción no se da por el plano en que se produce la falta, como parecen pretenderlo (existencia/validez). En ambos casos, lo que se está analizando es si el acto debe o no ser protegido por el derecho ${ }^{32}$. La diferencia radica en la gravedad del defecto. Se reserva la inexistencia para aquellos vicios que, por su entidad, se estima no deben ser saneados por la cosa juzgada. Volveremos al tema más adelante.

\section{3. ¿Se requiere de perjuicio para que haya inexistencia?}

No todo defecto procesal debe necesariamente derivar en la ineficacia del acto, sea a través de la nulidad o de otra técnica. Esto es lo que tradicionalmente se ha conocido como el "principio de trascendencia" y supone, en célebres palabras de Couture, que "las nulidades no tienen por finalidad satisfacer pruritos formales, sino enmendar los perjuicios efectivos que pudieran surgir de la desviación de los métodos de debate cada vez que esta desviación suponga restricción de las garantías a que tienen derecho los litigantes" ${ }^{\prime \prime 3}$. Tal como apunta Alsina, la ineficacia que se sigue de la nulidad debe tener una finalidad práctica, no procediendo la nulidad por la nulidad misma ${ }^{34}$.

El principio de trascendencia está consagrado en el inciso primero del artículo 83 del Código de Procedimiento Civil (CPC), que establece la nulidad para los casos en que la ley lo prevé expresamente y en "todos aquellos en que exista un vicio que irrogue a alguna de las partes un perjuicio reparable solo con la declaración de nulidad"35. La cuestión que surge, entonces, es si es que para los casos de inexistencia se requiere analizar también la existencia del perjuicio. En general, los autores promotores de la inexistencia parecen no cuestionarse el tema por asumir que "es un problema que antecede al de

30 Palacio (1993), p. 403.

31 Algunos autores sí lo admiten. Morón, por ejemplo, dice que es aquel que adolece de un defecto de tal envergadura que impide que el acto nazca como tal acto procesal; Morón (1957), p. 115.

32 Gorigoitía (2013), pp. 138 y ss.

33 Couture (2010), p. 352.

34 Alsina (1958), p. 85.

35 Gorigoitía (2013b), p. 582. 
la validez ${ }^{\prime \prime 36}$. Como el acto no llega a existir, entonces, no se llega a hacer la pregunta acerca de la validez.

El asunto, sin embargo, amerita alguna reflexión mayor, al menos desde la perspectiva de la auténtica relevancia de aquella situación a la que se le atribuye el carácter de inexistente. Cuando se lee el siempre dispar catálogo de cuestiones que podrían suponer inexistencia no es raro encontrarse con defectos formales del patrocinio, escritos sin firma ${ }^{37}$ o falta de autorización del ministro de $\mathrm{fe}^{38}$. Respecto a defectos de esta especie cabe preguntarse si resulta razonable atribuir tan drástica consecuencia a una situación que en realidad no ha afectado el devenir del juicio.

Por supuesto, habrá casos en los que el perjuicio no será lo determinante para hacer un juicio de valor negativo relativo a la validez (o existencia del acto). La falta de jurisdicción, por ejemplo, es un asunto en el que puede llegar a haber valores muy caros en juego, aun si no se llega a determinar un perjuicio para las partes. En casos como esos, el solo apartamiento del modelo normativo resulta suficiente para que el acto amerite la ineficacia. Esto también ocurre en la nulidad, con las que Alsina Ilama nulidades automáticas ${ }^{39}$, que buscan proteger otros valores, distintos de los de derechos de las partes ${ }^{40}$.

\section{Régimen procesal de la inexistencia}

\subsection{El acto inexistente no produce efecto alguno}

Se suele sostener que el acto inexistente, dadas sus características, no produce efecto alguno. Couture enseña que el acto inexistente "no solo carece en absoluto de efectos, sino que sobre él nada puede construirse" ${ }^{\prime 41}$. Serra, en términos similares, dice que "no solo el acto no es susceptible de producir sus efectos normales, sino que no tan siquiera puede producir efecto alguno" ${ }^{\prime 42}$. Más recientemente, Carrasco ha postulado que "la inexistencia excluye cualquier efecto jurídico porque ontológica y jurídicamente no es capaz de producir efectos jurídicos ${ }^{\prime \prime 4}$.

\footnotetext{
36 TAVOLARI (2000), p. 248.

37 Pozo (1991), p. 67.

38 Pozo (1991), p. 76.

39 Alsina (1958), p. 73.

40 Gorigoitía (2013b), p. 595

41 Couture (2010), p. 341.

42 Serra (1969), p. 461.

43 Carrasco (2012), p. 263.
} 
Hay dos formas de entender esta afirmación: (a) como una descripción o (b) como un juicio de valor.

(a) Si se toma como una descripción, que el acto inexistente no produzca efecto alguno sería una especie de caracterización de él. El acto inexistente no produciría efectos debido a una verdadera impotencia material de hacerlo ${ }^{44}$. $\mathrm{Si}$ llegara a producirlo, ya se estaría frente a un acto nulo y no inexistente ${ }^{45}$. $\mathrm{Si}$ esta caracterización es cierta, el ámbito de la inexistencia quedaría reducido a la excentricidad, sin mayor relevancia. Si el acto no ha producido efectos, no se advierte siquiera el interés de obtener su declaración, ya que esto significaría que nadie le ha reconocido autoridad alguna.

Bocksang, sin embargo, advierte que esta forma de acercarse a la inexistencia es incorrecta. Si bien habría una tendencia a la ineficacia, un acto inexistente perfectamente puede producir efectos, debido a situaciones como la buena fe o similares ${ }^{46}$. Sería perfectamente concebible un acto calificable de inexistente, cuyos efectos se buscaran retrotraer precisamente a través de la intervención judicial.

(b) Si se toma como un juicio de valor, la terminología empleada supondría una aguda confusión entre el plano del ser y del deber ser. Del juicio de valor relativo a la validez (o existencia, si se quiere) se estaría pasando al plano fáctico, asumiendo, erróneamente, que sólo porque un acto no deba producir efectos en los hechos no los produce. Con decir, entonces, que el acto no produce efectos se quiere decir que éste no debe producir efectos.

Esta última situación es particularmente relevante al momento de valorar si basta con una constatación o se requiere de la declaración de nulidad, como se analizará a continuación.

\subsection{La inexistencia se debe constatar, no es necesaria su declaración}

Junto con el hecho de que la inexistencia no produce efecto alguno, se afirma que ésta no requiere de declaración, bastando su constatación por el tribunal. El artículo 116 del Proyecto de Código Procesal Civil, en esa línea, se refiere a la "constatación de la inexistencia". En atención a que se trata de un "no-acto" no se requeriría de ninguna declaración judicial para que el acto se repute inexistente, aunque nada obsta a que ella, en caso de duda, se declare ${ }^{47}$. A partir de esta idea, algunos autores han sostenido que la inexistencia opera

44 Calmon (2009), p. 95.

45 HeRnÁNDEZ (1995), p. 77.

46 Bocksang (2013), p. 590.

47 Carrasco (2012), p. 261. 
de pleno derecho ${ }^{48}$, sin que requiera de invalidación ${ }^{49}$, pudiendo, simplemente, desconocerse la eficacia de los actos procesales sin necesidad de efectuar alegación alguna ${ }^{50}$.

Si se asumiera que esta figura opera sólo respecto de actos que no han producido efectos y que ni siquiera tienen la aptitud para hacerlo, lo anteriormente dicho podría resultar en general razonable. Para sostener que una sentencia dictada en una obra de teatro no produce efectos no se requiere ni de una sentencia ni de nada parecido. El problema surge cuando se afirma la inexistencia de actos con pretensión de validez y que han producido efectos. En esas circunstancias la declaración se vuelve ineludible, a riesgo de consentir actos de autotutela normalmente prescritos por el derecho. Un típico ejemplo de sentencia inexistente es la que se dicta por un juez que carece de jurisdicción $^{51}$. Si una sentencia con ese defecto dispusiera la restitución de un inmueble y se decretara el lanzamiento, ¿podría el condenado resistir la actuación de la fuerza pública o instar a la restitución por vías de hecho del inmueble? Evidentemente, no $^{52}$.

La necesidad de declaración de la inexistencia no escapa a las lógicas tradicionales de la función jurisdiccional. Será necesaria cuando las circunstancias de hecho así lo ameriten y algún interesado lo requiera, debido a las pretensiones de las partes que nazcan de ella ${ }^{53}$. Tal como ocurre en la nulidad, lo relevante no es si la sentencia es meramente declarativa o constitutiva, sino si algún interesado requiere de alguna declaración para tutelar un interés concreto. Lo que resulta impensable es que por el solo hecho de calificarse de inexistente una sentencia se autorice la autotutela para obtener una determinada prestación.

\subsection{No se subsana ni se convalida}

Junto con la caracterización anterior, se dice que el acto jurídicamente inexistente no es susceptible de ser saneado. Couture postula que "no puede

${ }^{48}$ Salas (2000), p. 76.

49 TAVOlari (2000), p. 248.

50 Colombo (1997), p. 434.

51 Romero (2014), p. 42. Sobre esto, es interesante la sentencia de la Corte de Apelaciones de Santiago, de 13 de septiembre de 2000, rol № 6921-2000, en ella se declara la inexistencia de un arbitraje en el que no había existido instalación. La necesidad de declaración era evidente, por cuanto era un juicio hasta entonces vigente, en el que incluso había embargos.

52 En el mismo sentido San Martín (2015), p. 768.

53 Guarinoni (2002), p. 39. 
ser convalidado" ${ }^{54}$. Otros autores, como Urrutia ${ }^{55}$ y Pozo $^{56}$, sostienen que son actos que no pueden sanearse. Tras estas afirmaciones subyace la idea de que la inexistencia, dada su gravedad, no es susceptible ni de ser corregida o subsanada por quien ha ejecutado el acto inexistente ni convalidada por quien se ve afectado por él. Si es que se estuviera pensando en la inexistencia como una cuestión meramente ontológica, esto no admitiría dudas, pues la nada no se puede corregir ni aceptar ${ }^{57}$. La cuestión se vuelve más compleja si es que se admite que el acto inexistente es, en definitiva, un acto, pero defectuoso, como parece necesario hacerlo. El saneamiento de un acto defectuoso es una cuestión que merece un mejor examen, diferenciando entre la subsanación y la convalidación, que tienen lógicas y límites distintos.

Entendemos por subsanación la corrección o integración de un acto procesal defectuoso, realizada normalmente por su autor, sea éste el órgano jurisdiccional o una de las partes ${ }^{58}$. El establecer que un acto sea subsanable, o no, es una cuestión que se relaciona con las características del defecto y con cuestiones vinculadas con la concepción que se tenga del proceso. No se relaciona necesariamente con la gravedad del acto. Por ejemplo, por grave que parezca que una sentencia carezca de parte resolutiva, ese defecto es perfectamente corregible a través de la complementación de la resolución.

Así entendido, no parece un despropósito admitir la subsanabilidad de un acto inexistente. Otero entiende que las situaciones relativas a la falta de patrocinio y comparecencia por persona no habilitada, reguladas en la ley $\mathrm{N}^{\circ} \mathbf{1 8 . 1 2 0}$, son casos de inexistencia "provisional y subsanable" ${ }^{59}$. Es lo que podría ocurrir con sentencias o escritos sin firma. Sobre las sentencias, Colombo constata que es un caso en el que se ha admitido la convalidación ${ }^{60}$. Respecto de los escritos, por su parte, Salas considera la firma como un requisito de existencia pero subsanable con la suscripción posterior ${ }^{61}$.

La convalidación es la aceptación de un defecto por parte de quien se ha visto afectado por ella. Ésta puede ser expresa, cuando se realiza en términos

\footnotetext{
54 Couture (2010), p. 341; en términos similares, Colombo (1997), p. 424; Tavolari (2000), p. 249; Carrasco (2012), p. 263.

55 URRUTIA (1928), p. 74.

56 Pozo (1991), p. 64.

57 Colombo (1997), p. 384.

58 Gorigoitía (2013), p. 144.

59 Otero (2009), p. 49.

60 Colombo (1997), p. 431.

61 Salas (1992), p. 167.
} 
formales y explícitos; o tácita, tanto cuando precluye la posibilidad de impetrar la nulidad como cuando se realice un acto que suponga aceptar la validez de lo actuado. En este caso, la invalidez desaparece no por la eliminación del defecto, sino por la falta de interés de quien se ha visto afectado por ella ${ }^{62}$.

El determinar si un acto es convalidable o no es una cuestión que tiene que ver principalmente con si hay un interés público comprometido y con el rol que se asigne al juez en el proceso ${ }^{63}$. Si se está pensando en la inexistencia para actos con defectos especialmente graves, entonces la imposibilidad de convalidar parece evidente, pero no distinta a lo que ocurre en la nulidad. Así, la falta de jurisdicción no es convalidable, pero tampoco lo es la incompetencia absoluta.

Sin embargo, igualmente es posible concebir casos de inexistencia convalidables. El mejor ejemplo es el de la falta de emplazamiento. Se suele decir que la falta de emplazamiento del demandado constituye un obstáculo insalvable para el perfeccionamiento de la relación procesal y que, por lo tanto, su ausencia supondría la inexistencia del juicio ${ }^{64}$. Sin embargo, tanto en el Código de Procedimiento Civil como en el Proyecto, la alegación de la falta de emplazamiento para la obtención de la declaración de nulidad o constatación de inexistencia debe hacerse en un plazo fatal (5 y 10 días, respectivamente, desde que aparezca o se acredite que tuvo conocimiento personal del juicio). Esto es claramente una convalidación tácita que deja en evidencia lo metafórico que es el uso del término inexistencia: transcurrido el plazo, el juicio que no existía pasa a existir con todas las propiedades del más perfecto de los juicios.

\subsection{Vías para obtener su declaración (o constatación)}

En el artículo 116 PCPC se establece un procedimiento especial de declaración de inexistencia, susceptible de ser promovido "en cualquier tiempo", que tiene como única exigencia el escuchar a los interesados. Esto es complementado por el artículo 122, que remarca que éste puede incoarse "en cualquier estado del procedimiento e incluso después de concluido", facultándose su declaración de oficio o a petición de cualquier interesado. Sólo se excluye de esta amplia oportunidad la recién referida situación de la falta de emplazamiento. En los términos en que se establece, se trataría de una declaración incidental hecha en el contexto de un juicio, sea que este se encuentre pendiente o ya afinado.

62 Gorigoitía (2013), p. 144.

${ }^{63}$ TAVOlari (2000), p. 272.

${ }^{64}$ Salas (2000), p. 100; Pereira (2011), p. 130. 
La situación actual es más compleja. Con la regulación vigente se han postulado principalmente tres medios de obtención de ella: (a) como una acción autónoma; (b) como un incidente, y (c) a través de la actuación oficiosa del juez.

(a) Según Colombo, la inexistencia puede ser alegada como acción. Dice que "si una persona se le trata de forzar a cumplir un acto procesal inexistente, podrá de una u otra forma accionar ante los tribunales para que éstos declaren que tal acto es inexistente ${ }^{\prime \prime 65}$. Aunque pudiera concebirse una acción meramente declarativa sólo para que se constatara que cierto acto no se ha verificado, si es que este acto tiene alguna apariencia de validez y su origen en un proceso determinado una actuación de esta especie estaría destinada a fracasar debido al asentado principio en nuestro ordenamiento procesal civil de que no se admiten procesos autónomos que busquen promover la ineficacia de lo actuado en otro juicio, salvo que sea a través de la acción de revisión ${ }^{66}$.

En el ámbito doctrinario, la procedencia de acciones autónomas de invalidación de actuaciones judiciales ha tenido una revitalización con el reconocimiento de la acción de nulidad de derecho público. El primer promotor de ésta como procedimiento autónomo que puede afectar a actos jurisdiccionales fue Soto $^{67}$. Siguiendo esta postura, Bocksang la ha postulado como una forma de alegar la inexistencia. Se funda en los artículos $7^{\circ}$ y $19 N^{\circ} 3$ de la Constitución ${ }^{68}$. El principal argumento para admitirla consiste en que ninguna expresión del artículo $7^{\circ}$ permitiría excluir restringirlo sólo a las actuaciones administrativas ${ }^{69}$. Este último autor admite una importante limitación: para no negar la función jurisdiccional, debe quedar "circunscrita al marco de aquellas violaciones a la legalidad procesal que sean de tal gravedad que impidan la constitución de la cosa juzgada, permitiendo perseguir sin límite de tiempo -imprescriptiblemente- la declaración de nulidad correspondiente" ${ }^{170}$.

65 Colombo (1997), p. 436.

66 Pozo (1991), p. 69; Carrasco (2011), p. 115. El mismo Mensaje del Código de Procedimiento Civil así lo reconoce, al decir que: "Terminan los procedimientos especiales con el que debe servir para el recurso de casación en la forma y en el fondo. No difiere el primero esencialmente del actual recurso de nulidad, pero se ha procurado Ilenar los vacíos y aclarar las dudas que en él se notan. Se determinan con tal objeto los trámites cuya omisión da lugar al recurso, y se desconoce de un modo expreso la acción ordinaria de nulidad para invalidar las sentencias, no admitiéndose otro camino que el de la casación para lograr ese resultado; en obsequio a la brevedad de los procedimientos y el tranquilo goce de los derechos declarados en juicio" (énfasis agregado).

67 Soto (1997), p. 348; también Otero (2009), p. 267.

68 Bocksang (2013), p. 601.

69 Bocksang (2013), p. 596. El énfasis es del original.

70 Bocksang (2013), p. 596. 
Como hace presente el mismo autor, la jurisprudencia y la doctrina no han sido receptivas de esta tesis, pues se cierran a la posibilidad de que lo ocurrido en un juicio pueda ser revisado en otro, por una vía que no sea la revisión. En un fallo reciente de la Corte Suprema, que resume una doctrina muy sostenida en el tiempo, se ha dicho que:

"En efecto, la referida nulidad de derecho público se hace derivar de los artículos $6^{\circ}$ y $7^{\circ}$ de la Constitución Política, el último de los cuales previene que 'Los órganos del Estado actúan válidamente previa investidura regular de sus integrantes, dentro de su competencia y en la forma que prescriba la ley'; que 'Ninguna magistratura, ninguna persona ni grupo de personas pueden atribuirse, ni aun a pretexto de circunstancias extraordinarias, otra autoridad o derechos que los que expresamente se les hayan conferido en virtud de la Constitución o las leyes' y que 'Todo acto en contravención a este artículo es nulo y originará las responsabilidades y sanciones que la ley señale'. Aunque estas disposiciones, junto con otras normas del ordenamiento vigente, enuncian el principio de legalidad a que debe someterse toda autoridad u órgano estatal y, entre ellos, los que ejecutan la función jurisdiccional, las mismas no autorizan una acción de nulidad en los términos en que se dedujo, puesto que la anulación de los actos que llevan a cabo los tribunales en ejercicio de la potestad jurisdiccional del Estado, debe perseguirse a través de los medios que franquea la ley procesal y que, sustancialmente, consisten en la declaración de nulidad de oficio o a petición de parte, que contemplan los artículos 83, 84 y 85 del Código de Procedimiento Civil, así como en los recursos de casación y revisión que regulan, respectivamente, los Títulos XIX y XX del Libro III del mismo texto o bien, excepcionalmente, por medio del ejercicio de las facultades disciplinarias de los Tribunales Superiores, conforme el artículo 545 del Código Orgánico de Tribunales.

De esta suerte, la nulidad de los actos jurisdiccionales pronunciados con infracción del artículo $7^{\circ}$ de la Constitución vigente, no podría reclamarse, en su caso, sino por las vías que contemplan dichas normas procesales, pues el sistema jurídico nacional no establece otros medios de impugnar los defectos de que pueden adolecer los procedimientos judiciales y los vicios de forma o de orden sustantivo que pueden afectar las resoluciones de los tribunales"71.

La doctrina, en general, se ha alineado con la misma idea, reivindicando que el derecho procesal reclama una especialidad en el tema de la nulidad que no puede desconocerse. Romero Seguel ha advertido que "si se admitiera la procedencia de la acción de nulidad de derecho público, en el ámbito jurisdiccional el debilitamiento de la cosa juzgada sería su más lógica

${ }^{71}$ Corte Suprema, rol № 3172-2015, de 27 de julio de 2015, el énfasis ha sido agregado. 
consecuencia"72. Carrasco, igualmente, remarca que "En virtud de la autonomía que detenta el Derecho procesal respecto del resto de las ramas jurídicas, no es posible mezclar instituciones que tienen distintos objetivos y fines, diversas características y protegen diferentes bienes jurídicos. En este sentido, las divergencias son plausibles. La nulidad de derecho público tiene por objeto anular actos que emanan de los órganos de la administración cuando éstos exceden las potestades atribuidas por la Constitución o la ley; la nulidad procesal, en cambio, busca sancionar las irregularidades que adolecen los actos jurisdiccionales desarrollados en los diversos momentos jurisdiccionales" ${ }^{\prime 73}$.

(b) Descartada la vía autónoma, la vía incidental se impone por su propio peso, pero tiene como gran inconveniente la necesidad de que ésta sea promovida mientras el juicio se encuentra aún vigente. Considerando, como se explicará más adelante, que la inexistencia sólo se vuelve relevante luego de firme la sentencia, se ha postulado la posibilidad de impetrarla a través del incidente de "rescisión por falta de emplazamiento", en la terminología del Código de Procedimiento Civil, que tiene la ventaja de poder ser alegado luego de concluido el juicio, según se deduce de lo que expresamente establecen los artículos 80, 182 y 234 del Código de Procedimiento Civil, cuestión que constituye una excepción al efecto preclusivo de la cosa juzgada ${ }^{74}$.

Rescisión -dice Pereira- "debe entenderse, con propiedad, que es inexistencia jurídica" ${ }^{\prime 75}$. Aunque las hipótesis que expresamente contempla el artículo 80 CPC puedan considerarse meramente ejemplares, esta incidencia sólo puede ser empleada dentro del marco de aplicación que contempla, es decir, para situaciones en las que se ha seguido un juicio en contra de una persona que no ha sido eficazmente emplazada ${ }^{76}$. Más allá de las dificultades que tiene el proponer una inexistencia convalidable, la discusión de si se trata de inexistencia, nulidad u otra cosa es irrelevante en lo relativo a la ampliación de los campos de proposición de la primera de ellas.

(c) Dado el panorama existente, la declaración oficiosa surge como una vía especialmente útil. Las amplias facultades que entrega el artículo 84 CPC para corregir de oficio los errores que observe en la tramitación del proceso abren la puerta a este tipo de intervenciones, en especial, cuando se ve en la inexistencia una grave afectación. Colombo propone que "aun cuando las partes nada digan

\footnotetext{
72 Romero (2003), p. 382.

73 Carrasco (2012), p. 214.

74 Salas (2000), p. 100; Carrasco (2010), p. 91.

75 Pereira (2011), p. 130.

76 En términos similares, Santa Cruz (1936), p. 63; Carrasco (2010), p. 90.
} 
sobre la inexistencia del acto tentado, el tribunal debe constatarlo y negar al acto jurídico todo efecto jurídico", cuestión que debiese ocurrir incluso si es que resulta que su aparición no es de manifiesto, remarcando, con ello, que se trata de una situación todavía más grave que la de la nulidad absoluta ${ }^{77}$.

Aunque resulta cuestionable, se han visto casos en los que se han hecho declaraciones de esta especie una vez concluido el juicio. Es lo que ha estimado la Corte de Apelaciones de Valparaíso, en un fallo de 18 de agosto de 2008, en que se afirma que "tratándose de requisitos de existencia, también el Tribunal puede, en base a las facultades que le son conferidas por el artículo 84 inciso final del Código de Procedimiento Civil, declarar la nulidad de oficio"178.

\section{La inexistencia y la nulidad}

Como se ha podido apreciar, las diferencias que se suelen predicar entre la nulidad y la inexistencia en realidad no son tales:

(a) Ambas, en definitiva, son técnicas para hacer ineficaces actos que tienen algún defecto, sólo que la inexistencia, entre quienes la promueven, se reserva para vicios de mayor gravedad;

(b) Tanto los casos que se reputan de inexistencia como de nulidad requieren de declaración judicial para eliminar sus efectos;

(c) En ambas, la convalidación y la subsanación pueden o no cumplir un papel dependiendo de las circunstancias concretas, y

\footnotetext{
77 Colombo (1997), p. 439.

${ }^{78}$ Corte de Apelaciones de Valparaíso, rol № 1161-2008, de 18 de agosto de 2008. Una aguda crítica a este fallo, y en particular a la posibilidad a ocupar el mecanismo del artículo 84 CPC se puede encontrar en: Gandulfo (2009), pp. 294 y ss. En un sentido similar actuó la Corte Suprema en casos en que un funcionario había actuado por delegación del Director del Servicio de Impuestos Internos en aplicación del entonces artículo 116 del Código Tributario: "Que en la especie ha existido respecto del tribunal que conoció de la causa falta de legitimación en el ejercicio de la jurisdicción, por lo que cabe concluir que de los tres presupuestos básicos de la relación procesal, a saber, el tribunal, las partes y la contienda, ha faltado el primero, es decir, no ha existido un tribunal con jurisdicción. Tal situación por su naturaleza puede ser observada en cualquiera etapa del juicio por el tribunal que esté conociendo de él y acarrea de un modo inevitable en nuestro sistema jurídico la correspondiente declaración de nulidad, lo que se hará en virtud de lo previsto en los artículos 83 inciso $1^{\circ}$ y 84 inciso final del Código de Procedimiento Civil". Esta postura contrasta con la prevención del Ministro Oyarzún, quien adhiere a la tesis de la inexistencia: "Que, en efecto, la formación de la relación jurídica procesal exige la concurrencia de diversos presupuestos de validez, de los cuales, el más importante es el de la investidura legal del juez que, como órgano del Estado, asume la función de resolver con la fuerza obligatoria que emana de su sentencia, el conflicto jurídico que las partes someten a su conocimiento y decisión. La ausencia del juez, sujeto principal de la relación jurídica, impide que ésta llegue a generar efectos vinculantes en el campo del derecho" (sentencia de 30 de julio de 2009, causa rol № 7170-2007). En el mismo sentido, las sentencias de 30 de junio de 2008 (rol № 2795-2007), de 12 de agosto del mismo año (2938-2007) y de 30 de julio de 2009 (rol No 6549-2007).
} 
(d) Las causales de inexistencia son perfectamente encausables a través de los motivos de nulidad durante la vigencia del juicio.

Nada de lo anterior debe llamar la atención. Las diferencias que se puedan pretender entre la severidad de los efectos entre la nulidad y la inexistencia no tienen que ver con cuestiones estructurales, sino con opciones políticas acerca de cómo subsiste el acto defectuoso ${ }^{79}$. En el mundo de los actos jurídicos, el binomio existencia/inexistencia no es distinto al de validez/invalidez, propio de las reglas potestativas ${ }^{80}$. Santamaría sostiene que "la inexistencia es, pues, una calificación metafórica que puede y debe subsumirse en la técnica de la nulidad, de cuyo seno nunca debió salir"81.

¿Por qué, entonces, siquiera se habla de la inexistencia? Es un lugar común para ilustrar su necesidad la archiconocida historia de su origen, al menos en la modernidad, relativa al matrimonio en Francia. Atrapado por la textualidad de la nulidad, y para salvar situaciones no reguladas como la unión de personas del mismo sexo, se postula la distinción entre cuestiones de existencia y de validez $z^{82}$. Se erige, la inexistencia, en una forma de salvar una verdadera laguna axiológica. Como explica Guarinoni, "como la solución que se encuentra en la ley no coincide con aquella axiológicamente deseable, el teórico busca formular una categoría pretendidamente descriptiva para acomodar la solución que prefiere ${ }^{\prime \prime 3}$.

En el derecho procesal, la textualidad o legalidad de la nulidad no es ya un problema. Ha evolucionado a un principio de especificidad ${ }^{84}$, que consiste en que la nulidad debe ser por estándares legales, cuestión que da flexibilidad suficiente como para que, al menos en ese punto, se haga improbable situaciones en las que resulte un límite incómodo.

Los problemas surgen por la cosa juzgada, en los casos en que los excepcionales mecanismos de remoción de ésta no resultan satisfactorios frente al caso concreto $^{85}$. En este punto es gráfico lo que dice la sentencia del caso "Novoa Chevesich con Servicio de Impuestos Internos", que en su considerando $17^{\circ}$

\footnotetext{
79 MAIer (2013), p. 140.

80 MaIer (2013), p. 137.

81 Santamaría (1972), p. 207.

${ }^{83}$ Guarinoni (2002), pp. 24-25.

${ }^{84}$ SAlas (2000), pp. 82 y ss.

85 HeRnández (1995), p. 75.
}

82 Sobre lo mismo, San Martín (2015), p. 263. Sostiene que: "En esta óptica la distinción conceptual entre requisitos de inexistencia y de validez carece de sentido, toda vez que lo jurídicamente pertinente no es cuestionarse si un acto jurídico existe o no, sino preguntarse por los límites a partir de los cuales es posible afirmar que un acuerdo o declaración de voluntad produce efectos jurídicos. Para determinar esos límites debe atenderse a lo que el acto precisa para ser eficaz conforme a derecho". 
afirma "Que la necesidad de enmendar una sentencia injusta debe incluso sobreponerse al efecto de la cosa juzgada, que tiene como justificación y fin la seguridad y estabilidad de los derechos" ${ }^{\prime \prime 6}$.

El carácter pragmático de la inexistencia es algo que queda en evidencia al analizar otras realidades. Es sintomático que en el proceso penal nacional, a pesar de tener bastante desarrollado el tema de la nulidad, no se haga mención a la inexistencia como una categoría relevante ${ }^{87}$. En situaciones en las que una categoría como ésta pudo haber resultado útil las salidas institucionales que se han buscado han sido otras, en línea con los mecanismos existentes, como la acción de revisión ${ }^{88}$ o el incidente de nulidad ${ }^{89}$.

Algo similar ha ocurrido en el proceso civil español. Si bien antes de la regulación sistemática de la nulidad, que data de la Ley Orgánica del Poder Judicial del año 1985, la discusión sobre el tema era relevante, el estudio dogmático de ésta y las categorías en ella contempladas hacen desaparecer tanto de la discusión doctrinaria como de la jurisprudencia toda apelación a esta categoría ${ }^{90}$.

\section{5. ¿En qué casos la inexistencia se vuelve una categoría relevante?}

Por lo que se ha explicado en el apartado anterior, la relevancia de la inexistencia está dada por la insuficiencia de la nulidad. Donde llega la nulidad, ésta es suficiente para hacer desaparecer el defecto, por grave que sea. Si esto es cierto, se deben analizar las situaciones en donde la nulidad choca con ciertos límites que desde el punto de vista valorativo no parecen satisfactorias. Analizaremos este asunto desde dos perspectivas: la cronológica y la causal.

\subsection{La inexistencia se vuelve relevante sólo una vez concluido el juicio}

Mientras el juicio está vigente, las vías para impetrar la nulidad son suficientes para resguardar todas las situaciones de presunta inexistencia. Sea a

${ }^{86}$ Corte de Apelaciones de Santiago, rol No 2540-1999, de 24 de mayo de 2000.

87 La excepción es NúÑ̃ez (2003), p. 397.

${ }^{88}$ Es lo que ha ocurrido en casos de suplantación de personas, en los que la persona que figura como condenado es distinta a la juzgada, por haberse entregado por el imputado una identidad ajena.

${ }^{89}$ Es lo que ocurrió en el caso de una falsa abogada, que defendió a ocho imputados en un juicio por tráfico de estupefacientes, en el año 2008. Cuatro años después quedó en evidencia que la defensora no era abogada. En ejercicio de sus facultades anulatorias, y de lo dispuesto en el artículo 160 del Código Procesal Penal, se anuló la notificación de la sentencia definitiva a la falsa abogada, disponiéndose una nueva notificación y la concesión de un nuevo plazo para recurrir de nulidad, la que fue acogida por afectación del derecho de defensa de los imputados. Corte Suprema, rol № 4060-2012, de 13 de julio de 2012.

90 Pereira Puigvert (2011), p. 97. 
través de las excepciones dilatorias, los incidentes de nulidad o los recursos, por grave que sea lo ocurrido, la nulidad se puede hacer cargo de ella. El que se conciban sin mayores problemas nulidades no susceptibles de convalidación y que se contemplen amplias facultades para decretar de oficio la nulidad, sea por medio de la casación de oficio o de las facultades correctoras del artículo $84 \mathrm{CPC}$, son garantías suficientes de que, de ser advertido un vicio grave, éste podrá ser eliminado ya sea a través de la declaración de nulidad, dependiendo del acto afectado.

Con el desarrollo de la inadmisión como técnica controladora de cuestiones que van más allá de lo meramente formal ${ }^{91}$, la posibilidad de controlar muchas situaciones que podrían originar inexistencia puede ocurrir incluso in limine con ocasión del examen de admisibilidad de la demanda. Es lo que se contempla en el PCPC, que permite inadmitir demandas, en entre otras hipótesis, por carecer de jurisdicción del tribunal, falta de capacidad de alguna de las partes "u otro defecto que afecte la existencia, validez o eficacia del proceso" (artículo 258, inciso segundo).

El problema surge una vez terminado el litigio. Desde los inicios del derecho procesal como ciencia se ha visto a la cosa juzgada como la "suma preclusión" ${ }^{\prime \prime 2}$, para dar a entender que ella produce el cierre de cualquier cuestión procesal o de fondo que se pueda haber dado durante un juicio ${ }^{93}$. En una opción que claramente se inspira en la seguridad jurídica ${ }^{94}$, se ha dicho que una vez hay sentencia ejecutoriada o un equivalente jurisdiccional toda cuestión relativa a su validez queda absolutamente cerrada, aun cuando se tratase sólo de cosa juzgada formal ${ }^{95}$, saneándose cualquier vicio que pudiese haber sido objeto de declaración de nulidad ${ }^{96}$. Se ha entendido que toda nulidad que no se alega in limine litis queda convalidada al momento de terminar el procedimiento ${ }^{97}$.

\footnotetext{
${ }^{91}$ La inadmisión es una técnica de control de los actos de parte que, entre otros objetivos, permite controlar in limine su validez, impidiendo la incorporación al proceso de actos defectuosos. La nulidad, en contraste, sólo es una técnica idónea para eliminar actuaciones judiciales y no de parte. La nulidad afecta actos de parte sólo cuando ellos ya han sido incorporados al proceso, y lo hace de forma indirecta, pues no es posible, por ejemplo, anular una demanda, sino solo la resolución que la admite, cayendo ésta sólo por un efecto reflejo. GorıGortía (2013), p. 146.

92 Chiovenda (1925), p. 358.

93 RAmos (2008), p. 1376.

${ }_{94}$ Oliva (2005), p. 116.

95 Pereira (2004), p. 127.

${ }_{96}$ Romero (2002), p. 35.

97 Salas (2000), p. 89.
} 
La imposibilidad de revisar la validez de lo terminado reconoce, con todo, excepciones respecto de defectos especialmente graves que han redundado en una sentencia injusta. Son casos en los que el valor de la seguridad jurídica cede frente a la justicia ${ }^{98}$. Cada sistema fija las hipótesis en las que se admite la derogación de la cosa juzgada y los mecanismos procesales para ello.

El sistema procesal civil chileno contempla procedimientos de revocación de juicios concluidos, pero en una clave claramente restrictiva, coherente con la alta valoración que se le da a la cosa juzgada, sólo derrotable en casos muy excepcionales ${ }^{99}$. Estos procedimientos son la acción de revisión de los artículos 810 y ss. CPC y la ya mencionada rescisión por falta de emplazamiento del artículo 80 CPC.

En un contexto de esta especie, en que se busca salvar los dogmas de la santidad de la cosa juzgada y de la limitación in limine litis, no extraña que se recurra a figuras patológicas como la cosa juzgada aparente (o la cosa no juzgada ${ }^{100}$ ) y la cosa juzgada fraudulenta ${ }^{101}$.

Respecto a la cosa juzgada aparente, Santa Cruz emplea el término "sentencias aparentemente ejecutoriadas" para referirse a las sentencias que tienen apariencia de estar firmes "pero que en realidad y jurídicamente no lo están"102, pues, en palabras de Hoyos, "habrá una materialidad de expediente o dossier, que será la vacua imagen de un proceso inexistente o nulo, induciendo a error a la masa de los justiciables"103. Siguiendo el mismo predicamento, Pereira explica que "una sentencia dictada en un proceso en que no han sido observados los presupuestos procesales aun ejecutoriada, no sanea esos vicios, pudiendo ser

\footnotetext{
98 LOURido (2003b), p. 508; MONTERo (2009), p. 256.

99 Romero (2002), p. 36.

100 Término, este último, empleado por Alsina (1958), p. 33.

101 Ambos términos también se han usado en procesos penales con una significación parcialmente distinta. La sentencia de la Corte Interamericana de Derechos Humanos, en el caso Almonacid Arellano y otros vs. Chile, de 26 de septiembre de 2006, dice, en su párrafo 154, que "En lo que toca al principio ne bis in idem, aun cuando es un derecho humano reconocido en el artículo 8.4 de la Convención Americana, no es un derecho absoluto y, por tanto, no resulta aplicable cuando: i) la actuación del tribunal que conoció el caso y decidió sobreseer o absolver al responsable de una violación a los derechos humanos o al derecho internacional obedeció al propósito de sustraer al acusado de su responsabilidad penal; ii) el procedimiento no fue instruido independiente o imparcialmente de conformidad con las debidas garantías procesales, o iii) no hubo la intención real de someter al responsable a la acción de la justicia. Una sentencia pronunciada en las circunstancias indicadas produce una cosa juzgada 'aparente' o 'fraudulenta'". Esta doctrina ha sido reconocida por la jurisprudencia nacional. Entre los casos más recientes, se puede ver la sentencia de la Corte Suprema, rol № 22658-2014, de 13 de abril de 2015.

102 SANTA CRUZ (1936), p. 81.

103 Horos (2001), p. 246.
} 
impugnada con posterioridad a su ejecutoria, porque jurídicamente son inexistentes el proceso, la sentencia, la ejecutoria y la cosa juzgada. Con eufemismo, se dice que en tal situación hay proceso y cosa juzgada aparentes" ${ }^{\prime 104}$.

La utilización de la noción cosa juzgada aparente puede suponer una simple apelación metafórica que busca poner en evidencia la gravedad de los vicios existentes, pero que asume que el proceso igualmente existe y que debe ser removido por las vías legales existentes ${ }^{105}$, o bien, una manera de desconocer el efecto saneador de la cosa juzgada y reivindicar la categoría de la inexistencia como algo independiente de la nulidad ${ }^{106}$.

El término cosa juzgada fraudulenta se emplea para referir a aquella sentencia firme ganada con algún tipo de maquinación dolosa. De acuerdo a Pacheco, "si ha existido este fraude, el proceso y menos su sentencia, cumplen ya con sus presupuestos de legitimidad y por lo mismo la cosa juzgada no cumplirá con los requisitos indispensables para ser inimpugnable ${ }^{\prime 107}$. A diferencia de lo que ocurre con la cosa juzgada aparente, en este caso, nuestro sistema sí contempla una manera de removerla, aunque con un marcado tinte restrictivo ${ }^{108}$, como es la acción de revisión por la causal tercera del artículo 810, que permite anular los juicios "ganados injustamente en virtud de cohecho, violencia u otra maquinación fraudulenta, cuya existencia haya sido declarada por sentencia de término". Postular en este caso la aplicación de la inexistencia, sería subvertir la voluntad del legislador que ha establecido un mecanismo claro y preciso para ello, más allá de las consideraciones de lege ferenda que se puedan hacer.

\subsection{Sólo la inexistencia del juicio puede llegar a ser trascendente}

La inexistencia se puede predicar respecto de un acto en particular o bien de todo un proceso ${ }^{109}$. La de un acto hace referencia a una actuación procesal, de cualquier sujeto, que no ha cumplido algún requisito que se estima especialmente grave. Por su parte, la inexistencia de un juicio supone un vicio que, más allá de que se pueda radicar en un acto concreto (normalmente, la demanda), pone en cuestión la validez del juicio en su totalidad.

Los autores hacen referencia a diversos actos procesales aislados que pueden ser de esta especie, tales como escritos o sentencias sin firma, la declaración de

\footnotetext{
104 Pereira (2004), p. 131.

105 Parece ser la posición de Hoyos (2001), p. 247; Romero (2002), p. 38.

106 Pereira (2004), p. 130.

107 PACHeCO (1998), p. 149.

108 Romero (2002), p. 36.

109 Urrutia (1928), p. 73; Colombo (1997), p. 423.
} 
un séptimo testigo sobre un mismo hecho o la falta de autorización por ministro de fe de un determinado acto. Respecto de todos ellos, la nulidad se puede hacer cargo sin mayores problemas. Estando en el contexto de un proceso judicial y asumiendo que si son suficientemente graves pueden llegar a considerarse inconvalidables, éstos pueden ser manejados por los medios y con las lógicas de la nulidad procesal. Parecería una desproporción y un auténtico atentado a la seguridad jurídica pretender que la valoración de un séptimo testigo o un problema relativo a las formalidades del patrocinio trascendieran el juicio y la cosa juzgada.

Las auténticas dificultades se dan respecto a la inexistencia del proceso en su totalidad ${ }^{110}$, cuestión que se daría básicamente por faltar algún presupuesto procesal ${ }^{111}$. Entendemos que son presupuestos procesales "aquellas circunstancias formales, establecidas en la ley procesal, que deben concurrir en el proceso para que sea posible la resolución sobre el fondo del asunto sometido a la consideración judicial, las cuales deben, además, observarse de oficio"1112.

Siguiendo a Romero, los presupuestos procesales se pueden agrupar en: (1) relativos al órgano jurisdiccional (jurisdicción, competencia e imparcialidad del juzgador); (2) relativos a las partes (capacidad procesal, postulación procesal y representación); (3) relativos al procedimiento (aptitud formal de la demanda, emplazamiento legal del demandado, adecuación del procedimiento y agotamiento de la vía administrativa previa) ${ }^{113}$.

Evidentemente, no todos los presupuestos procesales tienen la misma relevancia al momento de valorar las consecuencias de su ausencia ${ }^{114}$. Sólo excepcionalmente, un presupuesto procesal puede llegar a ser tan grave como para suponer que pueda trascender la cosa juzgada115. Parece evidente que defectos referentes a la competencia relativa, aptitud legal de la demanda o la adecuación del procedimiento, no ameritan que su cuestionamiento pueda exceder los márgenes del juicio.

Entre quienes predican la inexistencia como una categoría relevante, tres son los presupuestos procesales a cuya ausencia se le suele atribuir como

110 En una línea similar parece entenderlo Chiovenda, quien presta atención a la inexistencia de la relación procesal como categoría necesaria. CHIOvENDA (1925), p. 104.

111 Pereira (2004), p. 131; Otero (2009), p. 42; Colombo (1997), p. 428.

112 Romero (2014), p. 6.

113 Romero (2014), p. 9.

114 Carrasco (2012), p. 130.

115 Romero (2002), p. 39; Gandulfo (2009), p. 290. 
consecuencia la inexistencia: (a) la falta de jurisdicción; (b) la falta de capacidad para ser parte, y (c) la falta de emplazamiento.

(a) La falta de jurisdicción suele aparecer, aunque en distintas modalidades. Algunos la enuncian derechamente en esos términos (Urrutia ${ }^{116}$, Santa Cruz $^{117}$, Hoyos ${ }^{118}$, Colombo ${ }^{119}$, Bocksang $\left.{ }^{120}\right)$, mientras que otros sólo se refieren exclusivamente a la sentencia dictada por quien no es juez (Pozo ${ }^{121}$, Tavolari ${ }^{122}$, Salas $\left.{ }^{123}\right)$.

La diferenciación puede apuntar a un matiz importante. La falta de jurisdicción contempla diversas situaciones que van desde la sentencia de quien no detenta la calidad de juez, que puede ser calificado como un juzgamiento por una comisión especial, hasta otras de competencia internacional, en donde lo que se cuestiona, no es si quien está en frente está jurídicamente legitimado para hacerlo, sino la aplicación de una u otra regla de atribución de competencias entre diversos estados ${ }^{124}$. No todas merecen el mismo tratamiento.

Dentro de los casos de los juzgamientos por personas que no detentan la calidad de jueces, se pueden identificar aquellos en los que derechamente se está siendo juzgado por una comisión especial y otros relativos a los árbitros, cuando éstos exceden el tiempo o las materias propias de su encargo. Claramente, la primera situación es mucho más grave que la segunda. Supone una afectación a un derecho fundamental que debe ser de alguna forma remediada. En contraste, que lo resuelto con ocasión de un arbitraje sea validado por la cosa juzgada no presenta mayores inconvenientes. Así lo ha reconocido recientemente la Corte Suprema frente a una demanda que pretendió anular un arbitraje por haberse excedido en el plazo un juez partidor. Sobre el punto ha dicho que en este caso "correspondía se reclamara oportunamente la nulidad de los actos procesales en cuestión, de lo contrario o en el caso de haberse ello desestimado, ha de entenderse que éstos son actos procesales válidos y que rige por ello con toda su fuerza los efectos que le son propios,

\footnotetext{
116 URRUTIA (1928), p. 76.

117 Santa Cruz (1936), p. 90.

118 Hoyos (2001), p. 247.

119 Colombo (1997), p. 428.

120 BoCKSANG (2013), p. 599.

121 Pozo (1991), p. 60.

122 Tavolari (2000), p. 248.

123 Salas (2000), p. 76.

124 Colombo (2004), p. 579.
} 
de manera que no pueden atacarse por esta vía para así intentar revivir un proceso fenecido con autoridad de cosa juzgada"125.

Tampoco parece revestir una importancia capital que dentro de un juicio, y de lo naturalmente opinable que son muchas situaciones, se adopte una regla de competencia favorable a una jurisdicción por sobre otra, aun cuando ella pueda resultar discutible. Más allá de los temas de relaciones internacionales o de reconocimiento extranjero que en algunos casos esto pueda suponer, el que la cosa juzgada cierra aquella discusión está dentro de márgenes tolerables y hasta deseables, si se quiere privilegiar la seguridad jurídica ${ }^{126}$.

(b) La falta de capacidad para ser parte aparece con distintos énfasis en autores como Santa $\mathrm{Cruz}^{127}$ y Otero ${ }^{128}$, quienes identifican el problema de la capacidad para ser parte, o de la existencia legal de éstas, como una hipótesis de inexistencia. Es lo que ocurrió, por lo demás, en el caso "Novoa Chevesich con Servicio de Impuestos Internos", debido a la disolución de la sociedad demandante antes de la presentación de la demanda.

Sin perjuicio del creciente reconocimiento de capacidad a entes que carecen de personalidad jurídica ${ }^{129}$, la dificultad es real y puede generar dificultades prácticas, tanto respecto de entes incapaces para ser partes como de fallecimiento de personas en proceso personalísimos, como el divorcio ${ }^{130}$. Con todo, en la primera de estas hipótesis la cuestión sólo merece sobrevivir a la cosa juzgada en la medida de que el asunto no haya sido conocido durante el juicio. Si es que hay una sentencia que declara la capacidad, la autoridad de la sentencia firme debe zanjar el tema definitivamente.

\footnotetext{
${ }^{125}$ Corte Suprema, rol № 3172-2015, de 27 de julio de 2015. El énfasis ha sido agregado.

126 En este sentido, son interesantes las reflexiones efectuadas por la Corte Suprema, rol № 5969-2011, de 10 de abril de 2013. Se trata de un caso en el que se demanda a dos sociedades alemanas por los defectos en un implante coclear implantado en Chile a un menor de edad. Los demandados alegaron la falta de jurisdicción, sosteniendo que eran sociedades alemanas, sin domicilio en Chile. La Corte sostuvo que: "Sexto: Que, en consecuencia, considerando a la jurisdicción como un atributo de la soberanía y teniendo en cuenta que en el caso en estudio se trata de aparatos médicos deficientes, fabricados en el extranjero, que fueron implantados en Chile a un niño que tiene domicilio en el país, el cual sufrió, al igual que sus padres, perjuicios que deben ser indemnizados, no es dable sino aceptar la plena eficacia de la actuación de los Tribunales chilenos para resolver los asuntos sometidos a su decisión, sin que el argumento dado por las demandadas -empresa extranjera sin domicilio en el paíssea un elemento que permita, a un órgano que ejerce jurisdicción, excusarse de conocer los asuntos judiciales que se promuevan dentro del territorio de la República, cualquiera que sea su naturaleza o la calidad de las personas que en ellos intervengan".

127 SANTA Cruz (1936), p. 85.

128 Otero (2009), p. 45.

129 ROMERo (2014), p. 283

130 Véase, Gandulfo (2011), en particular pp. 293 y ss.
} 
(c) La falta de emplazamiento es otro asunto que suele reconocerse como causal de inexistencia. Urrutia, Santa Cruz ${ }^{131}$, Pereira ${ }^{132}$ y Salas ${ }^{133}$ ponen de relieve esta situación. En palabras del primero de ellos "si se sigue un juicio en contra de una persona que no es pretendido demandado no hay en su contra litigio alguno, no hay sentencia, ni hay cosa juzgada, porque la falta absoluta de emplazamiento no produce la relación procesal, que es el único vínculo que puede obligar a la parte a cumplir una sentencia judicial. De aquí que el acto de citación no sea una mera creación formal; hay un establecimiento de principios de Derecho Natural"134.

Aunque grave, esta situación se encuentra suficientemente cubierta por el incidente de rescisión o nulidad por falta de emplazamiento. Si bien antes ya había voces que la consideraban procedente ${ }^{135}$, al menos desde la entrada en vigencia de la ley $N^{\circ} 7.760$, de 1944 , se admite la posibilidad de pedir la rescisión por falta de emplazamiento incluso luego de terminado el juicio ${ }^{136}$. Se trata de un caso de nulidad sin necesidad de defectos procesales ${ }^{137}$, en el que por sobre la perfección de las formas se prefiere el hecho de que el demandado tenga verdadero conocimiento del juicio y tenga una auténtica posibilidad de ejercer su derecho a la defensa ${ }^{138}$. Aunque de la literalidad de la disposición se podría concluir que este incidente procede sólo por no haber llegado a las manos del demandado las copias en el caso de una notificación por cédula, se ha estimado, con buen criterio, que las menciones a las copias como sólo un ejemplo, entendiendo que el incidente procedería en todo tipo de notificación ${ }^{139}$.

En resumen, se puede apreciar que las situaciones en las que las soluciones relativas a la nulidad no resultan satisfactorias son la de algunos casos de falta de jurisdicción (aquellos que suponen un auténtico juzgamiento por una comisión especial) y los de falta de capacidad para ser parte, cuando el asunto no haya sido discutido durante el juicio. Sin que se puedan descartar otros, el tema es bastante más acotado de lo que los promotores de la inexistencia pretenden.

\footnotetext{
131 Santa Cruz (1936), p. 82.

132 Pereira (2004), p. 130.

133 Salas (2000), p. 76.

134 URRutia (1928), p. 76.

135 URRUTIA (1928), p. 166.

136 Pereira (2004), p. 130; Salas (2000), p. 97.

137 LoYOLA (2001), p. 133.

138 Gandulfo (2009), p. 151.

139 Santa Cruz (1936), p. 63; Carrasco (2010), p. 90.
} 


\section{Una propuesta: mejorar los mecanismos existentes relativos a la nulidad}

Frente a la constatación de insuficiencia del sistema de nulidad en determinados casos, hay dos opciones que muestran la tensión justicia/seguridad jurídica. La primera es, simplemente, asumir que la seguridad jurídica hace pagar ciertos costos de justicia, en los que las situaciones dificultosas antes reseñadas pueden caer. Es la opción de nuestro sistema vigente ${ }^{140}$. La alternativa es establecer vías más amplias de ineficacia de la cosa juzgada, en los casos en que ésta parezca más intolerablemente injusta. Es la opción del PCPC.

Si se asume que la segunda alternativa es más conveniente, la vía de la inexistencia parece excesivamente amplia y, además, remite a un aparato conceptual de muy difícil manejo. A la luz de esto, resulta más conveniente perfeccionar los sistemas actuales de nulidad posterior a la sentencia, a efectos de hacerlos más razonables. Eso es lo que, a continuación, se intentará proponer respecto del incidente de rescisión por falta de emplazamiento del artículo 80 CPC y la acción de revisión del artículo 810 CPC.

\subsection{El incidente de rescisión por falta de emplazamiento}

El artículo 80 CPC dispone que "si al litigante rebelde no se le ha hecho saber en persona ninguna de las providencias libradas en el juicio, podrá pedir la rescisión de lo obrado, ofreciendo acreditar que, por un hecho que no le sea imputable, han dejado de llegar a sus manos las copias a que se refieren los artículos 40 y 44, o que ellas no son exactas en su parte substancial. Este derecho no podrá reclamarse sino dentro de cinco días, contados desde que aparezca o se acredite que el litigante tuvo conocimiento personal del juicio".

Más allá del cambio de denominaciones, el inciso segundo del artículo 116 PCPC propone una fórmula similar: "en caso de falta de notificación de la demanda al demandado, dicha declaración deberá solicitarse dentro de los diez días siguientes desde que aparezca o se acredite que tuvo conocimiento personal del juicio".

Lo propuesto tiene sólo una ventaja en relación a lo existente, que es relativamente menor: aumenta el plazo para promover la incidencia, de cinco a diez días. En el resto, es más restrictivo o mantiene dificultades ya existentes.

EI PCPC restringe la incidencia a los casos de "falta de notificación al demandado". Aun entendiendo que la falta de notificación debe hacer referencia a la omisión de una notificación hecha de conformidad a la ley, desaparece la hipótesis relativa al hecho de que la notificación no llegue al poder del demandado por causas que no le resulten imputables.

140 Romero (2002), p. 40. 
En un sistema como el nuestro en el que la notificación no necesariamente significa una comunicación efectiva, sino protocolos de actuación que suponen una probabilidad de conocimiento que va decayendo en la medida de que esta se dificulta ${ }^{141}$, una restricción de esta especie excluye situaciones en las que formalmente la notificación fue realizada, pero en las que el demandado, por hechos no imputables a él, no ha llegado a tener conocimiento efectivo del juicio. Esto es particularmente difícil cuando, al mismo tiempo, se rebajan los estándares de las notificaciones ${ }^{142}$.

Además, se mantienen dos dificultades actuales. La primera es que deja como único legitimado al demandado, excluyendo toda posibilidad de que la falta de emplazamiento se transforme en una manera de control de casos de litisconsorcio necesario o, en general, en los que un tercero debió ser emplazado en un juicio $^{143}$. Es efectivo que el tercero tiene el derecho a alegar la inoponibilidad del fallo (artículo 234, inciso final CPC), pero eso sólo lo podrá hacer en la medida en que se intente una ejecución en su contra, lo que resulta insuficiente ${ }^{144}$.

La segunda dificultad tiene que ver con la muy complicada prueba del momento en que se ha tenido "conocimiento personal del juicio". La jurisprudencia ha sido exigente en este punto, por la presunción del artículo 427 CPC. Aunque en general esto parece razonable, debiese flexibilizarse, al menos en los casos en que no ha existido notificación alguna o ésta es manifiestamente defectuosa.

Un procedimiento incidental mejorado puede cubrir todas las situaciones en las que la falta de emplazamiento compromete no sólo la validez, sino la legitimidad del fallo. Para ello parece necesario que incluya: (1) una amplia legitimación no sólo al demandado, sino a terceros que debieron ser demandados;

141 Yelamos (2006), p. 353.

${ }^{142}$ El artículo 93 PCPC autoriza al ministro de fe a determinar in situ la procedencia de una notificación por cédula en subsidio de la personal, consolidando una tendencia que ya se apreciaba en el procedimiento del trabajo (artículo 437 del Código del Trabajo) y el procedimiento de familia, artículo 23, inciso segundo, ley № 19.968.

${ }^{143}$ En algunos casos, la jurisprudencia lo ha aceptado. En un fallo de 3 de julio de 1997, en la causa rol № 1111-1997, la Corte Suprema declaró que: "Que ante la apelación del Fisco interpuesta con arreglo al artículo 551 del referido Código, cabe puntualizar que de acuerdo con lo que disponen los artículos 80, 182 y 234 del Código de Procedimiento Civil, aplicables en materia laboral en virtud del Libro Primero de este Código y del artículo 426 del Código del Trabajo, el hecho de haber recaído sentencia de término no obsta a la promoción del incidente de nulidad de lo obrado por falta de emplazamiento. $Y$ aun cuando el Fisco no hubiese tenido el carácter de litigante, es lo cierto que tratándose de un vicio que anula el proceso por no haberse seguido contra legítimo contradictor, por los fundamentos consignados en la resolución del juez a quo, ha resultado suficiente su sola verificación para que el juez pudiera declarar la nulidad de todo lo obrado" (el énfasis ha sido agregado). Corte Suprema, rol № 1111-1997, de 3 de julio de 1997.

144 Romero (2014), pp. 266 y ss. 
(2) la posibilidad de reclamar situaciones de desconocimiento del juicio en casos en los que la notificación ha sido válida, pero no ha producido conocimiento real del juicio; (3) que dé un plazo razonable para preparar la incidencia desde el conocimiento real del juicio.

\subsection{La acción de revisión}

El principal procedimiento fijado para la remoción de la cosa juzgada es el de revisión de sentencias firmes que se contempla en el Título XX del Libro III $\mathrm{CPC}^{145}$. Este se basa en las estrictas hipótesis del artículo $810^{146}$, que requieren otra sentencia firme que declare la concurrencia de la causal indicada ${ }^{147}$. Su gran problema es que en materia civil es absolutamente irrelevante. En la última década, salvo error u omisión, se han acogido sólo dos acciones de revisión en materia civil, una fundada en cosa juzgada no alegada oportunamente ${ }^{148}$ y otra en la falsedad documental ${ }^{149}$.

La configuración de las causales fraudulentas $\left(\mathrm{N}^{\circ} \mathrm{s} .1\right.$ a 3), con la exigencia de que existan sentencias firmes que prueben la ilicitud, el plazo de un año para su presentación y la exclusión de toda resolución que haya sido dictada por la Corte Suprema ${ }^{150}$, explica lo infrecuente de las sentencias favorables. En

\footnotetext{
145 Romero (2002), p. 37.

146 Art. 810. La Corte Suprema de Justicia podrá rever una sentencia firme en los casos siguientes:

$1^{\circ}$. Si se ha fundado en documentos declarados falsos por sentencia ejecutoria, dictada con posterioridad a la sentencia que se trata de rever;

$2^{\circ}$. Si pronunciada en virtud de pruebas de testigos, han sido éstos condenados por falso testimonio dado especialmente en las declaraciones que sirvieron de único fundamento a la sentencia;

$3^{\circ}$. Si la sentencia firme se ha ganado injustamente en virtud de cohecho, violencia u otra maquinación fraudulenta, cuya existencia haya sido declarada por sentencia de término, y

$4^{\circ}$. Si se ha pronunciado contra otra pasada en autoridad de cosa juzgada y que no se alegó en el juicio en que la sentencia firme recayó.

El recurso de revisión no procede respecto de las sentencias pronunciadas por la Corte Suprema, conociendo en los recursos de casación o de revisión.

147 Mosquera y Maturana (2010), p. 574.

${ }^{148}$ Corte Suprema, rol № 3284-2004, de 2 de mayo de 2006.

${ }_{149}$ Corte Suprema, rol № 4763-2013, de 2 de diciembre de 2013.

150 Llama la atención el esfuerzo argumentativo de la Corte Suprema para resolver ese punto en la sentencia rol № 4763-2013: "Que, siguiendo en la misma línea argumentativa, debe consignarse que si bien consta que la sentencia dictada por la Corte de Apelaciones de Santiago, y que incide en el juicio ejecutivo que se pretende escrutar, fue objeto de recursos de casación en la forma y en el fondo por la parte demandada, del examen de la resolución emitida en su oportunidad por esta Corte se advierte que la nulidad formal impetrada fue declarada inadmisible, de conformidad con lo que prevé el artículo 781 del Código de Enjuiciamiento Civil y, por su parte, el arbitrio sustancial fue rechazado, haciendo uso este Tribunal de la facultad que confiere el artículo 782 del citado conjunto normativo, esto es, por adolecer de manifiesta falta de fundamento.
} 
el PCPC, si bien la redacción de la causal relativa a la prueba fraudulenta y la eliminación de la restricción respecto de las sentencias dictadas por la Corte Suprema amplían en algo espectro, el escenario sigue siendo bastante acotado ${ }^{151}$. Resultaría conveniente analizar la posibilidad de flexibilizar las causales, en especial en lo relativo a la exigencia de una sentencia firme anterior en la que se acredite una maquinación fraudulenta, tal como ocurre en el derecho español, en la que no se requiere de ésta ${ }^{152}$. Una ampliación de esta especie permitiría

En relación con lo anotado es útil consignar que según la doctrina hay casos en que el rechazo de un recurso de casación en el fondo por "manifiesta falta de fundamentos" implica un pronunciamiento de fondo y, en otros, ello no es así. Hay situaciones en las que, en la desestimación "in limine" del recurso no se evalúa la aceptación o negación de un fundamento casacional efectivo, sino que se atiende más bien a su formulación; esto, en lo referido a que su modo de intentarlo impide la evaluación para hacerlo, que es lo que ocurre, por ejemplo, si en el recurso no se impugnan normas "decisoria litis", lo que hace que el cuestionamiento de la sentencia sea más aparente que real, o no se señalan como vulneradas disposiciones reguladoras de la prueba, lo que no hace posible alterar los hechos establecidos por los jueces de instancia y que llevaron a la decisión atacaba. De otro lado, hay ocasiones en que el rechazo del recurso "in limine", por "manifiesta falta de fundamentos", configura un antejuicio de fondo, que involucra un verdadero pronunciamiento de tal naturaleza, lo que tiene lugar, también a vía de ejemplo, cuando no se hace lugar a un recurso de casación sustancial por estar bien fallada la causa. En este caso el rechazo es similar al fallo previa tramitación completa, salvo por la dinámica procesal de la intervención de las partes. Corte Suprema, rol № 4763-2013, de 2 de diciembre de 2013. Por consiguiente, habiéndose en la situación en estudio declarado inadmisible el recurso de casación en la forma, por no reunir los requisitos exigidos por la ley para que pueda tramitarse y resolverse y, a su vez, desestimado "in limine" el recurso de casación en el fondo por manifiesta falta de fundamentos, al no haberse dado en él por conculcadas normas decisoria litis e ir contra hechos, procede concluir que esta Corte no emitió un pronunciamiento de fondo sobre el asunto, y este aserto nos conduce a colegir, de manera consecuencial, que en el caso sub lite no hay impedimento alguno para conocer de la presente acción de revisión".

151 "Art. 222.- Causales de revisión. Se podrá demandar la invalidación de una sentencia definitiva firme sólo en los casos siguientes:

1. Si alguna de las pruebas que constituyeren fundamento decisivo de la resolución impugnada hubiere sido declarada falsa por otra sentencia firme.

2. Si la sentencia se hubiere obtenido en virtud de prevaricación, cohecho, violencia u otra maquinación fraudulenta, cuya existencia haya sido declarada por sentencia ejecutoriada; y

3. Si se hubiere pronunciado contra otra pasada en autoridad de cosa juzgada y que no se alegó en el juicio en que la sentencia firme recayó".

152 El artículo 510 de la Ley de Enjuiciamiento Española establece como causales las siguientes: 1. Habrá lugar a la revisión de una sentencia firme:

$1^{\circ} \mathrm{Si}$ después de pronunciada, se recobraren u obtuvieren documentos decisivos, de los que no se hubiere podido disponer por fuerza mayor o por obra de la parte en cuyo favor se hubiere dictado.

$2^{\circ} \mathrm{Si}$ hubiere recaído en virtud de documentos que al tiempo de dictarse ignoraba una de las partes haber sido declarados falsos en un proceso penal, o cuya falsedad declarare después penalmente.

$3^{\circ} \mathrm{Si}$ hubiere recaído en virtud de prueba testifical o pericial, y los testigos o los peritos hubieren sido condenados por falso testimonio dado en las declaraciones que sirvieron de fundamento a la sentencia. $4^{\circ} \mathrm{Si}$ se hubiere ganado injustamente en virtud de cohecho, violencia o maquinación fraudulenta.

2. Asimismo se podrá interponer recurso de revisión contra una resolución judicial firme cuando el Tribunal Europeo de Derechos Humanos haya declarado que dicha resolución ha sido dictada en 
cubrir fraudes que desde la perspectiva penal pueden resultar irrelevantes o que permiten salidas alternativas, como podría ser el ocultamiento del domicilio del demandado para motivar la notificación por avisos ${ }^{153}$.

\section{Conclusiones}

a. Las situaciones relevantes de inexistencia se dan respecto de actos con pretensión de validez y que muchas veces han producido efectos jurídicos. Como consecuencia de esto, la ineficacia que se pueda derivar de ella requiere de declaración judicial.

b. Los defectos procesales que pueden Ilevar a las hipótesis de inexistencia pueden ser subsanables o convalidables, con las mismas lógicas y consideraciones de la nulidad.

c. No hay una diferencia sustancial entre la nulidad y la inexistencia. Las dos son mecanismos que buscan hacer ineficaces actos procesales defectuosos. Entre quienes la aceptan, la inexistencia se reserva a aquellos defectos más graves, que por su entidad no deben ser saneados por la cosa juzgada.

d. Antes de que un juicio se encuentre concluido, los defectos que se suelen reconocer de inexistencia son remediados mediante la nulidad y, en menor medida, la inadmisión. La inexistencia, en consecuencia, sólo se vuelve relevante una vez concluido el juicio.

e. De los motivos de inexistencia que se suelen citar por la doctrina, sólo aquellos que se identifican con algunos presupuestos procesales tienen la entidad suficiente para eventualmente trascender la cosa juzgada. Los defectos que puedan acarrear la inexistencia de actos precisos en caso alguno debiesen trascender al juicio en que se producen y pueden ser, por lo tanto, resueltos por medio de la nulidad.

f. La regulación que propone el PCPC es una radical ruptura con el sistema actual de remoción de la cosa juzgada. De un sistema marcadamente restringido, que privilegia la seguridad jurídica, se pasaría a otro en el que ésta se debilitaría notoriamente por la posibilidad de "constatar" la inexistencia en cualquier tiempo.

g. Con el objeto de hacerse cargo de las insuficiencias del sistema actual de remoción de la cosa juzgada, resulta mejor perfeccionar las vías existentes

violación de alguno de los derechos reconocidos en el Convenio Europeo para la Protección de los Derechos Humanos y Libertades Fundamentales y sus Protocolos, siempre que la violación, por su naturaleza y gravedad, entrañe efectos que persistan y no puedan cesar de ningún otro modo que no sea mediante esta revisión, sin que la misma pueda perjudicar los derechos adquiridos de buena fe por terceras personas.

153 Ramos (2008), p. 1523. 
para obtenerla (la rescisión por falta de emplazamiento y la acción de revisión), en vez de incluir a la figura estudiada, de muy inciertos límites, como se ha visto.

\section{Bibliografía CitADA}

Alsina, Hugo (1958): Las nulidades en el proceso civil (Buenos Aires, Ediciones Jurídicas Europa-América).

Baraona González, Jorge (2011): La nulidad de los actos jurídicos (Bogotá, Pontificia Universidad Javeriana).

Bocksang Hola, Gabriel (2013): "La inexistencia jurídica de los actos jurisdiccionales", en Revista Chilena de Derecho (Vol. 40, № 2), pp. 577-608.

Calmon de Passos, José Joaquim (2009): Esboço de Uma Teoria das Nulidades Aplicadas às Nulidades Processuais (Río de Janeiro, Forense).

CARnelutti, Francesco (1944): Sistema de derecho procesal civil (Traducc. Niceto Alcalá-Zamora y Castillo y de Santiago Sentís Melendo. Buenos Aires, UTEHA), tomo I.

Carrasco Poblete, Jaime (2010): La rebeldía en los procesos civil y laboral (Santiago, LegalPublishing).

CARRASCo Poblete, Jaime (2012): La nulidad procesal como técnica protectora de los derechos y garantías de las partes en el Código de Procedimiento Civil chileno, tesis doctoral (Santiago, Universidad de los Andes).

Chiovenda, Giuseppe (1925): Principios de derecho procesal civil (Traducc. José Casáis Santaló, Madrid, Editorial Reus), tomo II.

Chiovenda, Giuseppe, (1949): Ensayos de derecho procesal, II (Buenos Aires, Ediciones Jurídicas Europa-América).

Colombo Campbell, Juan (1997): Los actos procesales (Santiago, Editorial Jurídica de Chile), tomo II.

Colombo Campbell, Juan (2004): La competencia, segunda edición (Santiago, Editorial Jurídica de Chile).

COUTURE, Eduardo J. (2010): Fundamentos de derecho procesal civil, cuarta edición (Reimpresión), (Santiago, LegalPublishing).

De la Oliva Santos, Andrés (2005): Objeto del proceso y cosa juzgada en el proceso civil (Navarra, Aranzadi, Cizur Menor).

Gandulfo Ramírez, Eduardo (2011): "Presupuestos procesales y su decaimiento en los juicios personalísimos. La capacidad procesal en el caso 'Quezada Arias con Farías Lauri'", en Revista de Derecho Universidad Católica del Norte (No 1), pp. 281-299. 
Gorigoitía Аввотt, Felipe (2013): "Irregularidad, invalidez e ineficacia en el contexto de la nulidad procesal", en Revista de Derecho de la Universidad Católica del Norte (Vol. 20, № 1), pp. 129-154.

Gorigortía AввOtt, Felipe (2013b): "El perjuicio reparable sólo por la declaración de nulidad como estándar de invalidez de las actuaciones procesales civiles", en Revista de Derecho de la Pontificia Universidad Católica de Valparaíso (Vol. 40, No 1), pp. 575-599.

GuarinONI, Ricardo Víctor (2002): "De lo que no hay. La inexistencia jurídica", en Doxa, Cuadernos de Filosofía del Derecho (№ 25), pp. 637-656.

HeRnÁndez GalileA, Jesús (1995): La nueva regulación de la nulidad procesal (Oviedo, Forum).

Hoyos Henrechson, Francisco (2001): Temas fundamentales de Derecho Procesal (Santiago, LexisNexis).

Loyola GonzÁlez, Eugenio (2001): Los incidentes de nulidad (Santiago, La Ley). Lourido Rico, Ana María (2003): La nulidad de actuaciones: una perspectiva procesal, segunda edición (Granada, Comares).

Lourido Rico, Ana María (2003b): "La articulación de las relaciones entre la seguridad jurídica y la justicia: la cosa juzgada y algunos de los mecanismos procesales que permiten desconocerla", en: Anuario da Facultade de Dereito da Universidade da Coruña ( $\left.N^{\circ} 7\right)$, pp. 493-510.

MAIER, Julio B.J. (2013): Función normativa de la nulidad, segunda edición (Buenos Aires, Ediciones Adhoc).

Montero Aroca, Juan et al. (2009): Derecho Jurisdiccional II: proceso civil (Valencia, Tirant lo Blanch).

Morón Palomino, Manuel (1957): La nulidad en el proceso civil español (Barcelona, Ahr).

Mosquera Ruiz, Mario y Maturana Miquel, Cristián (2010): Los recursos procesales (Santiago, Editorial Jurídica de Chile).

NúÑez VÁsquez, J. Cristóbal (2003): Tratado del proceso penal y del juicio oral (Santiago, Editorial Jurídica de Chile).

Otero Lathrop, Miguel (2009): La nulidad procesal civil, penal y de derecho público (Santiago, Editorial Jurídica de Chile).

Pacheco Valderrama, Christian (1998), Fraude procesal (Ediciones Jurídicas Congreso).

PAlACIO, Lino Enrique (1993), Manual de derecho procesal civil, décima edición (Buenos Aires, Abeledo-Perrot).

Pereira Anabalón, Hugo (2004): La cosa juzgada en el proceso civil, segunda edición actualizada (Santiago, LexisNexis). 
Pereira Puigvert, Silvia (2011): La ineficacia de los actos procesales: sistematización y clarificación de conceptos (Madrid, Marcial Pons).

Pozo Siıva, Nelson (1991): De las nulidades procesales, segunda edición (Santiago, La Ley).

Ramos MénDEZ, Francisco (2008): Enjuiciamiento civil: cómo gestionar los litigios civiles (Barcelona, Atelier), tomo II.

Romero Seguel, Alejandro (2001): "El control de oficio de los presupuestos procesales y la cosa juzgada aparente", en Revista Chilena de Derecho (Vol. 28, № 4), pp. 781-789.

Romero Seguel, Alejandro (2002): La cosa juzgada en el proceso civil chileno (Santiago, Editorial Jurídica de Chile).

Romero Seguel, Alejandro (2003): "La improcedencia de la nulidad de derecho público para revisar resoluciones judiciales, como precedente judicial", en Revista Chilena de Derecho (Vol. 30, № 2), pp. 381-385.

Romero Seguel, Alejandro (2014): Curso de derecho procesal civil (Santiago, La Ley), tomo II.

Salas Vivaldi, Julio E. (2000): Los incidentes y en especial el de nulidad en el proceso civil, penal y laboral, séptima edición actualizada (Santiago, Editorial Jurídica de Chile).

SAn Martín, Lilian (2015): "La teoría de la inexistencia y su falta de cabida en el Código Civil chileno", en Revista Chilena de Derecho (Vol. 42, № 3), pp. 745-784.

SANTA CRUz SerRANO, Víctor (1936): Ensayo sobre la teoría de las nulidades procesales en el Código de Procedimiento Civil chileno (Santiago, Imprenta Chile).

SANTAMARÍA PASTOR, Juan Alfonso (1972): La nulidad de pleno derecho de los actos administrativos (Madrid, Instituto de Estudios Administrativos).

Serra Domínguez, Manuel (1969): "Actos procesales ineficaces", en Estudios de Derecho Procesal (Barcelona, Ariel), pp. 459-467.

Sото Kıoss, Eduardo (1997): "Nulidad de derecho público: su actualidad", en Revista de Derecho Pontificia Universidad Católica de Valparaíso (Vol. 18, $\mathrm{N}^{\circ} 1$ ), pp. 347-355.

Tavolari Oliveros, Raúl (2000): "La nulidad procesal en el derecho actual", en El proceso en acción (Santiago, Libromar), pp. 49-84.

UrRUtia Salas, Manuel (1928): Nulidades procesales (Santiago, Imprenta y Encuadernación Víctor Silva).

Yelamos Bayarri, Estela (2006): Nulidad procesal y comunicaciones judiciales fallidas (Barcelona, Atelier). 